\title{
ISOLATION AND MULTIPLE OUTPUT EXTENSIONS OF A NEW OPTIMUM TOPOLOGY SWITCHING DC-TO-DC CONVERTER
}

\author{
R.D.MIDDLEBROOK AND SLOBODAN ĆUK \\ Colifornia Institute of Technology \\ Pasadena, California
}

\section{ABSTRACT}

The recently introduced new optimum topology $d c-t o-d c$ converter is extended in a simple and elegant manner to provide dc isolation and multiple outputs. In comparison with the single-transistor isolated forward and flyback converters operated under the same conditions, the single-transistor isolated new converter is shown to have equal or lower stress levels on the transistor, diode, and capacitor ripple current, and can utilize an isolation transformer with lower core and copper losses. Measurements of cross- and self-regulation properties of a two-output $45 \mathrm{w}$ test converter are presented.

\section{Introduction}

A new dc-to-dc converter, Introduced at the 1977 PESC [1], was described as having an "optimun topology" configuration because f.t provides the basic dc-to-dc conversion property with the smallest number of elements that permit both the input and output currents to be nonpulsating. The potential performance, efficiency, and cost benefits to be obtained by use of the new converter were described, and a favorable comparison was made with the conventional buck-boost converter, which has the same dc-to-dc transformation property as does the new converter.

In its original form as described in [1], the new converter is a nonisolated polarity inverting converter. Since many practical applications demand dc isolation, there is strong motivation to extend the new converter configuration to incorporate an isolation transformer. This paper introduces a simple and elegant solution to this problem, in which the original single-transistor converter is augmented merely by a single-ended isolation transformer and an additional capacitance [2].

Similarly simple single-transistor, singleended transformer-isolated versions of the conventional buck and buck-boost converters are well-known respectively as the "forward" and "flyback" converters. If the ncw isolated converter

This work was supported in part by the Naval Ocean Systems Center, San Diego, California, through MIPR No. N0095377MP09018, and by the International Business Machines Corporation, Kingston, New York. is to be viable, its properties must compare favorably with those of comparable forward and flyback converters. In this paper a detailed comparison is made which shows that the new converter has distinct advantages in almost all respects.

In particular, the transistor and diode current and voltage stress levels, and capacitor ripple current stress levels are, in most operating conditions, less in the new converter than in the forward or flyback converters. If the same isolation transformer core and copper are used in all three, the copper loss also is less in the new converter; however, a core of half the area can in fact be used in the new converter, which leads to half the core loss and even lower copper loss than in the forward or the llyback converter.

Once an 1solation transformer is introduced, extensions to multiple outputs of various polarities are obvious, and examples are given. Not so obvious is the fact that any or all of the input and output inductors in the multiple-output new converter can be coupled (wound on the same core) with lowered ripple current properties (even zero), as has been described for the original nonisolated converter [3].

Finally, some experimental results on a twooutput isolated new converter are presented together with measurements on the cross- and selfregulation properties, which are of concern when the converter is embedded in a feedback loop in which only one output is regulated. This configuration is typical in computer power supplies, among others.

\section{The original optimum-topology new converter}

The simplest form of the new converter circuit is shown in Fig. 1. Its basic operation and properties have been discussed in [1], and will be only briefly summarized here.

The salient feature of the new converter is that its properties closely approach those of an adjustable-ratio dc-to-dc transformer, which is the desired objective of any such converter. The dc voltage transformation ratio $M$ is given by $M=D / D^{\prime}$, where $D$ is the duty ratio (fractional on-time) of 

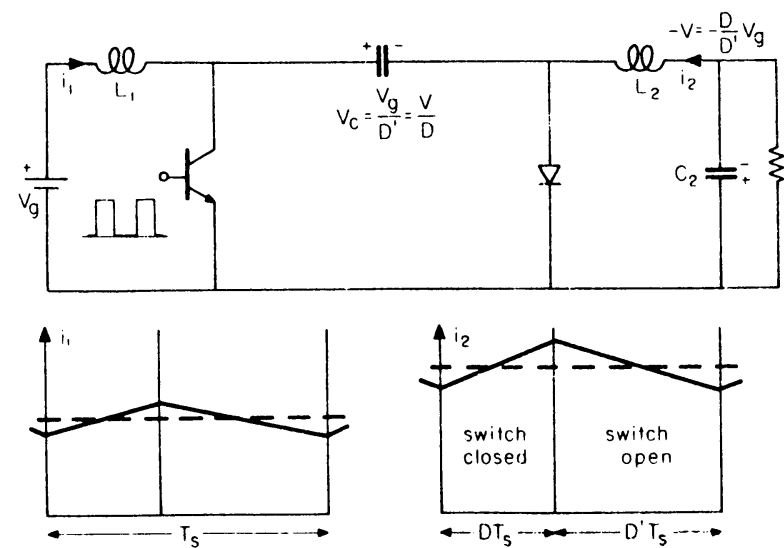

Fig. 1 The original new optimum-topology converter, and the nonpulsating input and output current waveforms.

the transistor switch operated at switching frequency $1 / T_{S}$, and $D^{\prime}=1-D$ is the complementary duty ratio (fractional off-time), when the converter is operated in the continuous inductor-current mode (neither inductor current falls to zero at any time). For a dc input-voltage $v_{g}$, the output dc voltage (polarity inverted) is $\mathrm{V}^{\mathrm{g}}=\mathrm{MV}_{\mathrm{g}}$. The converter has the same transformation ratio as the conventional buck-boost converter, giving a buck or step-down ratio for $D<0.5$ and a boost or step-up ratio for $D>0.5$. The other principal feature is that both the input and output currents are nonpulsating (in the continuous inductor current mode), and consist of a dc component with a comparatively small superimposed switching ripple, as also shown in Fig. 1.

Because the input and output inductor currents are essentially constant the switched current is confined entirely within the converter, in the loop formed by the capacitance $\mathrm{C}$, transistor, and diode. When the transistor is off, during the interval $\mathrm{D}^{\prime} \mathrm{T}$, the input current charges $\mathrm{C}$ and the diode carries the sum of the input and output currents; when the transistor is on, during the interval DT the diode is open, the transistor carries the sum of the input and output currents, and $C$ discharges into the load. It may therefore be said that $C$ is a coupling or energy transffer capactince, since it stores energy from the input during $D$ 'T and delivers it to the load during DT; this is accomplished by effectively switching $\mathcal{S}$ between the input and output circuits. It is easily shown that the average voltage on the coupling capacitance is $\mathrm{v}_{\mathrm{c}}=\mathrm{v}_{\mathrm{g}} / \mathrm{D}^{\prime}=\mathrm{V} / \mathrm{D}$.

Furthermore, in the most straightforward design, $C$ is large enough that its voltage ripple is fractionally small so that its voltage is essentially constant at the average value $V_{\text {c }}$; this result is analogous to that of making the inductances large enough that their respective current ripples are fractionally small.

From yet another point of view, it may be said that energy storage and delivery proceeds simultaneously in two loops in both switch intervals.
During DT, the input and output loops are closed through the transistor; energy is stored in $L_{1}$ from the input, and energy is released from $\mathrm{C}$ to $\mathrm{L}_{2}$ and the load. During $D^{\prime} T$, the input and output loops are closed through the diode: energy is released from the input and $L_{1}$ and is stored in $C$, and simultaneously energy is released from $L_{2}$ to support the load. This symmetry of the basic new converter is the source of its efficiency advantages and also makes possible several useful extensions $[3,4,5]$ besides those to be introduced here.

\section{Development of the isolated version of the new converter}

The original new converter of Fig. 1 provides a single, polarity inverted, nonisolated output. For many applications it is essential to provide dc isolation between input and output, and/or multiple outputs of different voltages and polarities.

There is therefore a strong incentive to find a way to introduce an isolation transformer into the original new converter, and the obvious place to do this is somewhere in the inner loop containing the coupling capacitance, transistor, and diode in which the aforementioned switched energy transfer current exists. There are three steps to a simple, elegant solution to this problem.

The first step is to separate the coupling capacitance $C$ into two series capacitances $C$ and $C_{b}$. The second is to recognize that the connection point between these two capacitances has an indeterminate average or dc voltage, but that this dc voltage can be fixed at zero by connection of an inductance between this point and ground. If the extra inductance is large enough, it diverts a negligible current from that passing through $\mathrm{C}_{\mathrm{a}}$ and $C_{b}$ in series, and so the converter detailed operation is so far unaffected. The third step is merely the separation of the extra inductance into two equal transformer windings, which thus provide the desired dc isolation between input and output.

The result of these three steps is shown in the basic isolated version of the new converter in Fig. 2. With a 1:1 transformer, the voltages and currents in the input and output circuits are the same as in the original nonisolated version. The only difference is that the switched current loop now becomes two loops with equal currents circulating in the same direction.

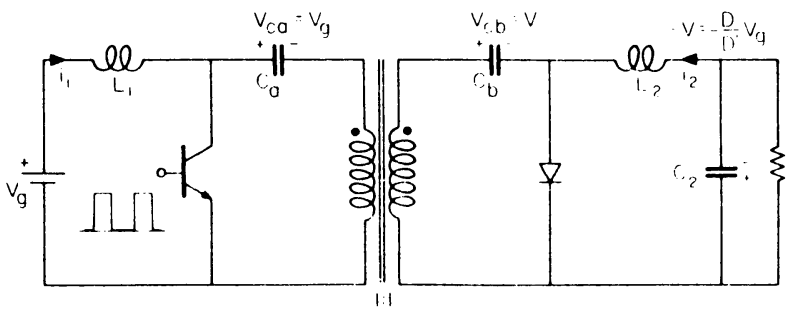

Fig. 2 The new converter with a $1: 1$ isolation transformer: all the advantages of the original converter are retained. 
The salient feature of the isolation method shown in Fig. 2 is that both windings of the transformer are dc blocked by $\mathrm{C}$ and $\mathrm{C}$, and therefore there can be no dc in either winding and so automatic volt-second balance 18 achieved. Thus, there is no problem of core operating point creep as can occur in push-pull "balanced" Isolation arrangements. It follows that, since there can be no average or dc voltage across either transformer winding or either inductance in the circuit of Fig. 2, the voltage on $\mathrm{C}_{\mathrm{a}}$ is $\mathrm{v}_{\mathrm{ca}}=\mathrm{v}_{\mathrm{g}}$ and that on $c_{b}$ is $v_{c b}=v$. It may be noted that ${ }^{g}$ $v_{c}+v_{c b} \cong v_{0}+v=v_{o} / D^{\prime}=v / D$, the same as the voltage ${ }^{c}$ achoss the single coupling capacitance $C$ in the original converter of Fig. 1.

It is instructive to consider the current paths, voltage distributions, and energy dispositions during the two switch intervals. In Fig. $3(a)$, conditions are shown during interval $D^{\prime} T$, when the transistor 18 off. The input current charges $\mathrm{L}_{1}$ and $\mathrm{C}_{a}$, and an equal reflected current in the transformer secondary charges $C_{b}$. The output inductance $\mathrm{L}_{2}$ discharges into the load, and the diode carries the sum of the input and output currents. The width of the current path in Fig. 3(a) suggests that the input current $i_{1}$ is smaller than the output current $1_{2}$, which would be the case for $D$ less than 0.5. Arrows pointing upwards (downwards) ind icate elements in which energy is being stored (released). In Fig. 3(b) for interval DT when the transistor is on, the input current charges $L_{1}$, the reflected discharge current of $C_{\text {also discharges } C} C_{b}$ and charges $\mathrm{L}_{2}$ and supplies the load; the transistor again carries the sum of the input and output currents.
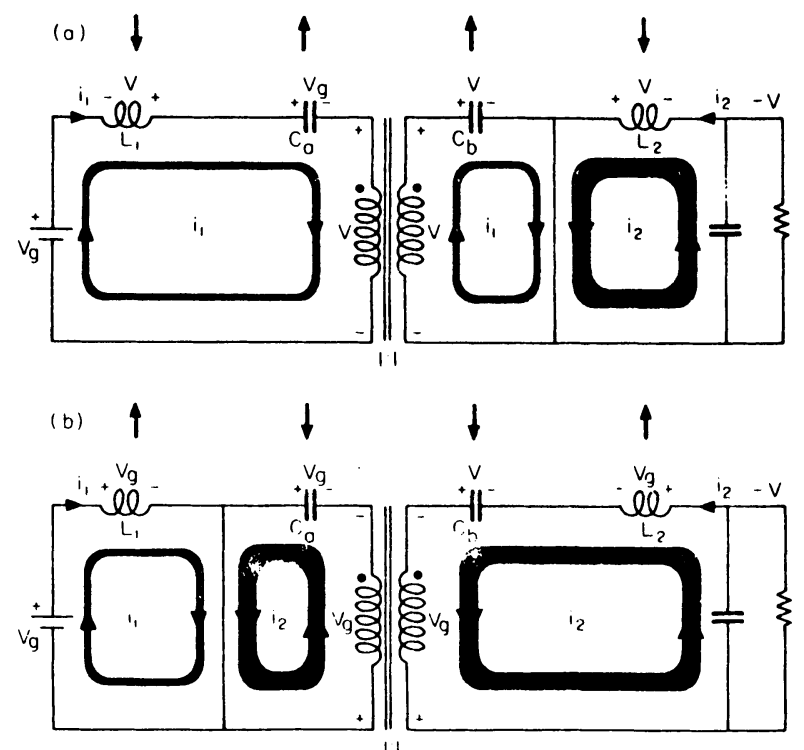

Fig. 3 Current and voltage distributions in the isolated new converter: (a) interval D'Ts when the transistor switch is open; (b) interval DT when the switch is closed. Uppointing arrows indicate energy storage in the adjacent element; down-pointing arrows indicate ene igy release.
Isolation has thus been achieved in the simplest possible manner by addition only of the necessary transformer (which is single-ended), and the only other modification is separation of the original coupling capacitance into two. Consequently, the configuration of Fig. 2 may be sald to represent an opt Imum-topology dc-1solated new converter.

\section{Comparison of the new converter with single- transistor 1solated forward and flyback converters}

The dc isolated version retains all the features of the original new converter, including a single switching transistor, with a "singleended" isolation transformer. The compelling simplicity of this circuit immediately invites comparison with familiar single-transistor isolated converters, such as the buck "forward" and the buckboost "flyback."

Three possible disadvantages of the new converter come to mind. One concerns the two coupling capacitances $C$ and $C_{b}$ : these capac1tances transfer the entire power (in ac form) from Input to output, and therefore are called upon to handle a substantial ac current. It may appear, therefore, that the esr of these capacitors (or, more directly, their ripple current stress rating) would Impose a more severe 1 imitation upon the power handling capacity of the new converter than on, say, the forward converter in which the principal energy transfer is through magnetic rather than electric field energy storage.

The other two possible disadvantages concern the stress levels in the switching transistor and diode. To first order, the stress levels may be defined as the "on" current $I$, and the "off" voltage $V_{\text {f }}$. In the new converter, both the transistor and diode carry the suin of the input and output currents, and so perhaps $I$ is higher than in either the forward or the flyback converters in which the transistor carries only the input current and the diode carries only the output current. In the new converter, which may be viewed as a coalesced boost-buck converter, the series inputinductance $L_{1}$ obviously causes the transistor offvoltage to be substantially higher than the input voltage, and so perhaps $v$, 18 higher than in efther of the other two converters.

We shall see in this section that all three of these conclusions are false: the capacitor ripple current requirements and the transistor and diode stress levels are in fact the same in the new converter as in the conventional single-transistor forward and flyback converters. Moreover, there remain other net advantages in the new converter, particularly with respect to the size (and Jnsses) of the isolation transformer. 


\subsection{Cepacitor, transistor, and diode comparative strese level.}

To compare more quantitatively these converters, let us set up the three circults to provide the same basic conversion performance. Suppose a one-to-one isolated voltage conversion 18 required so that $\mathrm{V}=\mathrm{V}$, and consequently (with neglect of losses) the iffput and output dc currents are each equal to some value I determined by the load resistance. Further, let the switch be driven at a duty ratio $D=0.5$ in each case.

The three circuits are shown in Figs. 4,5, and 6 , together with the transformer primary and secondary voltage and current waveforms $v_{p}, 1_{p}$ and $v_{s}$, 1 appropriate to the chosen operatihg condition $D^{8}=0.5$. For simplicity it 18 assumed that the Inductances and capacitances are large enough that both current and voltage ripples are negligible, and transistor and diode forward drops are 1gnored.

In the new converter of Fig. 4, the transformer turns ratio is $1: 1$ in order to obtain $V=V$ with $D=0.5$; the two coupling capacitances $C$ and $C_{b}$ thus each has the voltage $v_{\text {. The relative winding }}$ polarity of the transformer ${ }^{8}$ secondary is reversed
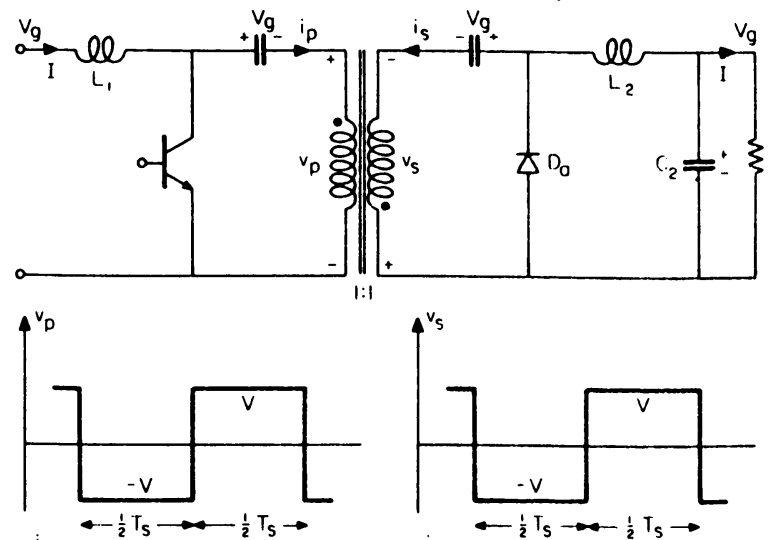

$\varphi^{\prime}$

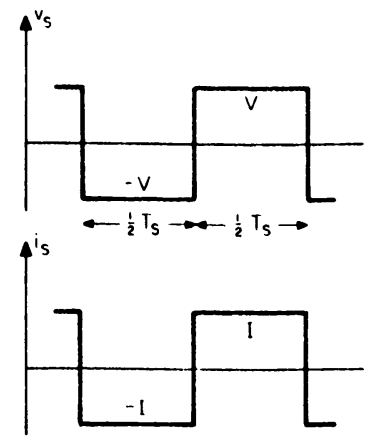

Fig. 4 The new converter with $1: 1$ isolation transformer, and primary and secondary voltage and current waveforms for $D=0.5$ for which $V=V_{g}$.

compared to that of Fig. 2 so that a positive output voltage is obtained as in the corresponding forward converter of Fig. 5, in which the transformer ratio must be $1: 2$ in order to have $V=V$ with $D=0.5$. The zener diode, necessary for $t$ rahisformer core reset, must have a breakdown voltage $v_{\text {, }}$ of at least $2 \mathrm{v}_{\text {f }}$ in order that transformer core reset be achleved before the end of the switching cycle; actually, an additional margin would have to be allowed, as shown in the dashed volt age waveforms in Fig. 5. An input filter $\mathrm{L}_{1} \mathrm{C}$ is included for proper comparison with the new converter of F1g. 4;
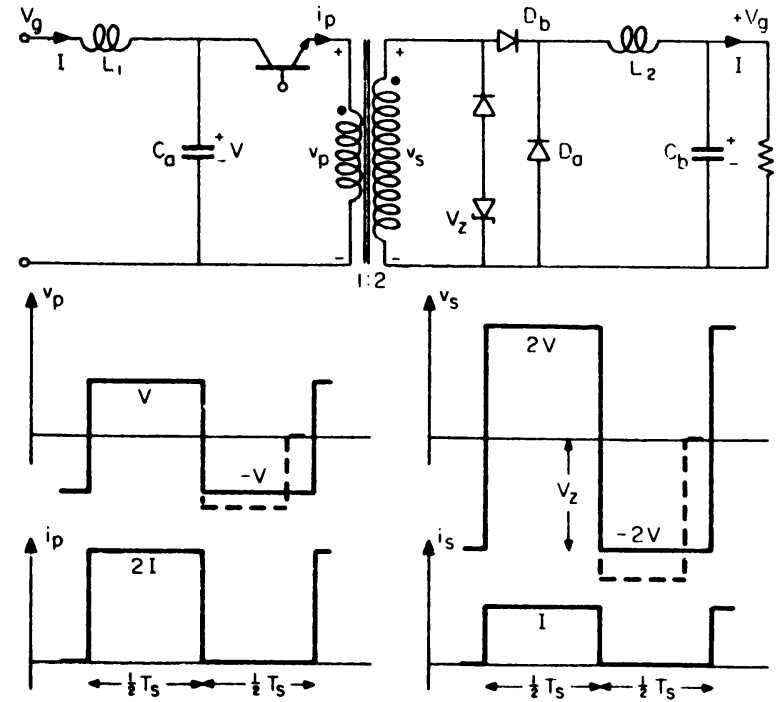

Fig. 5 Transformer voltage and current waveforms in a "forward" converter configured to give $V=V$ with $D=0.5$, for comparison with those ${ }^{g}$ of Fig. 4.
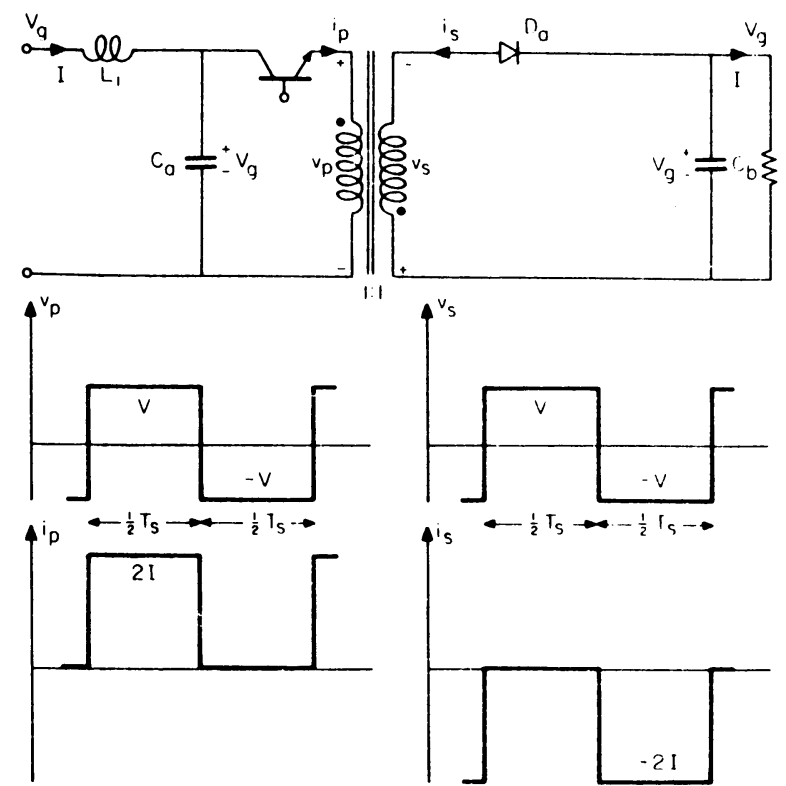

Fig. 6 Transformer voltage and current waveforms in a "flyback" converter configured to give $V=V$ with $D=0.5$, for comparison with those of Fig. 4.

even if the input inductor $L_{1}$ were omitted in the forward converter of $\mathrm{F} 1 \mathrm{~g}$. $5,{ }^{1}$ the capacitor $C_{\text {would }}$ still be essential to keep the pulsating input current from being drawn from the $v$ supply. In the comparable flyback converter of Fig. 6 , the required transformer ratio is again $1: 1$ so that $V=V_{0}$ when $D=0.5$. An input filter $L_{1} C$ is also inclided to make the input current nonpulsating.

Comparison of the three converters is now easily made by inspection of the circuits and wave- 
forms in Figs. 4, 5, and 6. In the new converter of Fig. 4, each coupling capacitor $C_{\text {and }} C_{\text {carries }}$ a square wave current $I$, and so the ripple current rating requirement is $\mathrm{I} \mathrm{rms}$, which is indeed substantial. However, it is seen in Fig. 5 that the current in the input capacitance $C_{8}$ is $I-1$, which also has an rms value of $I$. The same is ${ }^{\text {true }}$ for Fig. 6: each capacitor $C_{\text {and }} C_{b}$ carries a ripple current of I rms. Furthermore, in all three circuits, the operating voltage of each capacitor is $\mathrm{v}_{\text {. Therefore, the same ripple current rating }}$ is required on the capacitors in all three converters; the only difference is that the forward converter requires one such capacitor whereas the flyback and the new converter each requires two (the output capacitor $\mathrm{C}_{2}$ in the forward and in the new converter does not have severe ripple current requirements).

It is also easily seen from Figs. 4, 5, and 6 that the transistor in each converter has to pass an on-current of $2 I$ and has to withstand an off-

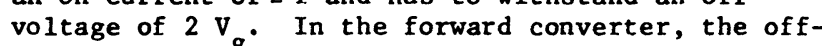
voltage exceed $2 \mathrm{~V}$ if the reset zener has a breakdown voltage greate 8 than $2 \mathrm{v}_{g}$. Therefore, the stress ratings represented by ${ }^{g} I$ and $V$, for the transistor are the same in all three conterters. Consequentiy, the transistor dissipation 18 also the same in all three.

The same result is true for the diodes: the off-voltage $V_{\text {off }}$ is $2 \mathrm{~V}_{\text {f }}$ in all three circults; the on-current I of 18 I for the new converter and for the flyback; ${ }^{\text {of }}$ or the forward converter, two diodes $D_{\text {and }} D_{b}$ are required each to carry an on-current $I^{a}=I . b$ Consequent $1 y$, the total diode on-losses are the same in all three converters.

Contrary to the initial impression, therefore, the stress levels on the principal components are the same in all three single-transistor isolated converters, and the new converter is at no disadvantage. Let us now consider the design of the isolation transformer itself in each converter.

\subsection{Comparative isolation transformer properties}

In the new converter of Fig. 4 the 1solation transformer has no dc current component in either winding, and leakage inductance can be minimized by use of an ungapped torold of square-loop material. If the same core and primary winding of resistance $R$ is used in the forward converter of Fig. 5, the secondary will have twice the number of turns of half the wire area to keep the same copper crosssection as in the new converter.

The core and copper are thus set up to be the same in the forward as in the new converter. However, a1though the core loss is therefore the same, tr: copper loss in the forward converter is double that in the new converter. This occurs because in the primary, the mean square current is twice as large in the forward as in the new converter, and so the $\overline{i_{p}^{2}} R$ losses are doubled in the same winding resistance. In the secondary, the mean square current is half as large in the forward converter, but the winding resistance is $4 R$ because of double the number of turns at half the wire size, so the secondary $i_{S}^{2} R$ losses are also doubled.

There is a further difference: for use in the forward converter the square-loop core must be gapped, since magnetizing current is avallable in only one direction, and the remanent flux must be reduced to a small value. The effect of this gap is 1llustrated in Fig. 7. In the forward converter, therefore, the core size must be chosen so that the total flux excursion is not greater than the saturation flux $B$. In contrast, in the new converter, magnetizing current is available in both directions, and so a core that is fully utilized in the forward converter is only half utilized in the new converter. Therefore, a core of half the crosssection could be used in the new converter so that the total flux excursion would be $2 \mathrm{~B}$, and as a result the core loss would be halved. The halved area in turn leads to even lower copper loss because the winding lengths are reduced.

Overall, therefore, a smaller, ungapped squareloop core can be used in the new converter than the gapped core necessary in the forward converter, which results in an isolation transformer in the new converter that has lower core loss and lower copper loss. From a general point of view these benefits all stem from the fact that, in the new converter, power is transmitted through the transformer from the input to the output during both intervals of the switching cycle, whereas the same average power has to be transmitted during only one interval in the forward converter.

Comparison of the transformer properties in the flyback and new converters shows that the disparity is even more extreme, because in the flyback the core gap must be larger than in the forward converter, as also illustrated in Fig. 7. This is because the transformer is really an inductor, since the transmitted energy is stored in the magnetic field (princtpally in the air gap) during one interval of the switching cycle and is released to the output

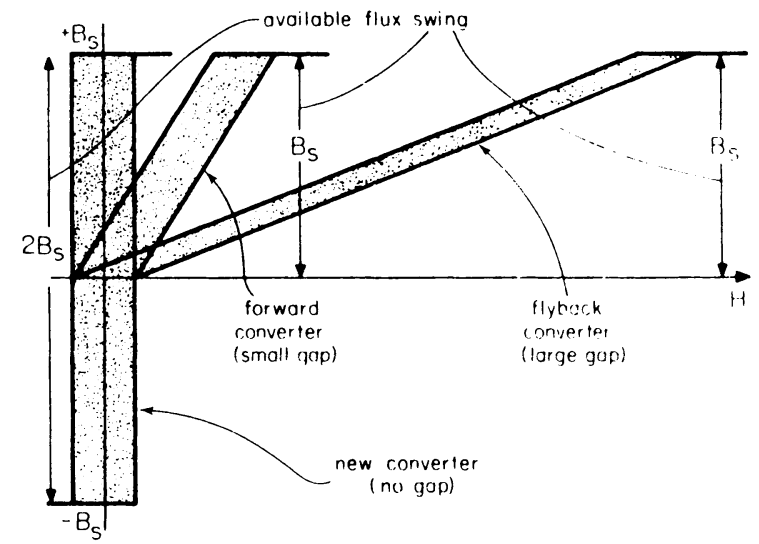

Fig. 7 Comparison of isolation transformer core utilization in the new converter and the forward and flyback converters. Twice the flux swing is available in the new converter. 
during the other interval. Consequently, the magnetizing current, which is again available in only one direction, constitutes the total primary or secondary current instead of just a small fraction of it.

\subsection{Comparison of the three converters at different operating points}

The discussion so far of the comparative properties of the three single-transistor 18olated converters has been for one operating condition, $\mathrm{D}=0.5$ that gives $\mathrm{V}=\mathrm{V}_{\text {g }}$ for all three, since this is a convenient symmetrieal case. Comparison of the various stress levels and losses is easily accomplished for other operating conditions, and the results for the original operating point and for two others are assembled in Table 1.

\begin{tabular}{|c|c|c|c|c|c|c|c|c|c|}
\hline & \multicolumn{3}{|c|}{$V=0.5 V_{g}$} & \multicolumn{3}{|c|}{$V=V_{g}$} & \multicolumn{3}{|c|}{$V=15 V_{q}$} \\
\hline & 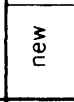 & \begin{tabular}{|l|}
0 \\
0 \\
3 \\
3 \\
\\
\end{tabular} & \begin{tabular}{|l|} 
\\
0 \\
0 \\
\end{tabular} & 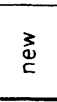 & \begin{tabular}{|l|}
0 \\
0 \\
3 \\
3 \\
0 \\
\end{tabular} & 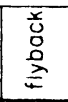 & $\underset{\text { d् }}{\text { c }}$ & $\begin{array}{l}0 \\
0 \\
0 \\
3 \\
0 \\
\end{array}$ & $\int_{i=1}^{x}$ \\
\hline D & 0.33 & 025 & 0.33 & 05 & 0.5 & 0.5 & 0.6 & 075 & 06 \\
\hline $\begin{array}{l}\text { primary } \\
i_{p}^{2} R \text { loss }\end{array}$ & $0.5 \mathrm{I}^{2} \mathrm{R}$ & $I^{2} R$ & ${ }^{0}{ }^{7} 5_{I_{R}^{2}}$ & $I^{2} R$ & $2 I^{2} R$ & $21^{2} \mathrm{R}$ & $15 I^{2} R$ & $31^{2} R$ & ${ }^{3} 7 \mathrm{I}_{\mathrm{F}}^{2}$ \\
\hline $\begin{array}{l}\text { secondary } \\
i_{s}^{2} R \text { loss }\end{array}$ & $0.5 I^{2} R$ & $I^{2} R$ & $15 l^{2} R$ & $I^{2} R$ & $2 \mathrm{I}^{2} \mathrm{R}$ & $2 I^{2} R$ & $15 I^{2} R$ & $3 I^{2} R$ & $25 \mathrm{I}^{2} \mathrm{R}$ \\
\hline$C_{a} \frac{\text { ripple }}{i_{c o}^{2}}$ & $0.5 \mathrm{I}^{2}$ & $0.75 \mathrm{I}^{2}$ & $0.5 \mathrm{I}^{2}$ & $\mathrm{I}^{2}$ & $\mathrm{I}^{2}$ & $\mathrm{I}^{2}$ & $15 \mathrm{I}^{2}$ & $0751^{2}$ & $1.5 \mathrm{I}^{2}$ \\
\hline$C_{b} \frac{\text { ripple }}{i_{c b}^{2}}$ & $05 \mathrm{I}^{2}$ & - & $0.5 \mathrm{I}^{2}$ & $1^{2}$ & - & $\mathrm{I}^{2}$ & $15 \mathrm{I}^{2}$ & - & $15 \mathrm{I}^{2}$ \\
\hline $\begin{array}{c}\text { Transistor } \\
\mathrm{I}_{\text {on }}\end{array}$ & $15 \mathrm{I}$ & $2 \mathrm{I}$ & $15 \mathrm{I}$ & $2 \mathrm{I}$ & 21 & $2 \mathrm{I}$ & $2.5 \mathrm{I}$ & $2 \mathrm{I}$ & $2.5 \mathrm{I}$ \\
\hline $\begin{array}{c}\text { Transistor } \\
V_{\text {off }}\end{array}$ & $15 V_{g}$ & $2 v_{g}$ & $15 V_{g}$ & $2 V_{g}$ & $2 v_{9}$ & $2 v_{g}$ & $25 V_{g}$ & $4 V_{g}$ & $25 V_{g}$ \\
\hline $\begin{array}{c}\text { Diode } D_{0} \\
I_{\text {on }}\end{array}$ & 151 & I & 151 & 21 & I & 21 & 251 & 1 & 2.51 \\
\hline $\begin{array}{c}\text { Diode } D_{0} \\
V_{\text {off }}\end{array}$ & $15 \mathrm{Vg}$ & $2 v_{g}$ & $15 V_{g}$ & $2 V_{g}$ & $2 v_{g}$ & $2 V_{g}$ & $25 v_{9}$ & $2 v_{g}$ & $2.5 \mathrm{~V}_{\mathrm{g}}$ \\
\hline $\begin{array}{c}\text { Diode } D_{b} \\
I_{o n}\end{array}$ & - & I & - & - & I & - & - & I & - \\
\hline $\begin{array}{c}\text { Diode } D_{b} \\
V_{\text {off }}\end{array}$ & - & $2 v_{g}$ & - & - & $2 v_{g}$ & - & - & $6 V_{g}$ & - \\
\hline
\end{tabular}

Table 1. Comparison of capacitor ripple current, transistor, and diode stress levels, and of transformer copper losses, in the three converters of Figs. 4, 5, and 6 operated at three different output voltages.

The comparison conditions are as follows. The three circuits are In Figs. 4, 5, and 6, and the isolation transformer core, for simplicity, is again taken to be the same for all three (except ungapped for the new converter, and appropriately gapped for the other two). The primary winding has the same number of turns of the same wire size for all three, and has a resistance $R$. Again, the secondary winding is the same as the primary for the new converter and for the flyback, with resistance $R$, but in the forward converter the secondary has twice the number of turns of half the wire area, and so has a resistance $4 \mathrm{R}$; thus, the total copper area is the same for all three converters.
Although the transformer turns rat to is selected so that $V=V_{0}$ for $D=0.5$ for all three converters, other outpat voltage settings require a different $D$ for the forward converter than for the other two because of the different effective transformation ratio, as noted in Table 1. The three operating points for which results are given in Table 1 are $\mathrm{V}=0.5 \mathrm{v}_{g}, \mathrm{~V}=\mathrm{v}_{\mathrm{g}}$, and $\mathrm{V}=1.5 \mathrm{v}_{\mathrm{g}}$. In each case, the output current is designated $l^{\circ}$. For each operation point, the table shows the transformer primary and secondary resistance losses $1^{2} R$; the mean square ripple currents $i^{2}$ and $i^{2}$ in the capacitors $C_{\text {and }} C_{b}$; the transistor (firstorder) stress levels $I$ and $V_{\text {f }}$; and the corresponding stress levels in the dioges $D_{a}$ and $D_{b}$.

The center group of results in Table 1 , for $V=V$ 'sumarizes the results already discussed in detall. The stress levels are the same for all three converters (except that the forward converter has two diodes each carrying half the current of the single diode in the other two converters), and the transformer primary and secondary copper losses are each twice as high in the forward and flyback converters as in the new converter.

In the left-hand group of results in Table 1 , for $V=0.5 \mathrm{v}_{g}$, it is seen that the transformer

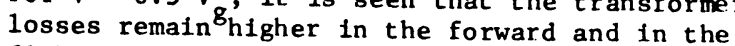
flyback converters, and the disparity is increased in the flyback secondary. The $C$ capacitor ripple current is now higher in the forward converter than in the other two, and both the current and voltage stress levels in both the transistor and diode are higher (counting the two diodes together). It is assumed that the reset zener voltage is sti11 $2 \mathrm{~V}_{g}$, the same as for the $D=0.5$ operating condition. $g$ '

In the right-hand group of results, for $\mathrm{V}=1.5 \mathrm{~V}_{\mathrm{g}}$, the transformer losses remain higher in the forwald and flyback converters, and the disparity is increased in the flyback primary. Although the $C_{a}$ ripple current and the transistor and diode oncurrents are smaller in the forward converter than in the other two, the voltage stress levels are considerably higher; this results from the requirement that the reset zener must have a higher

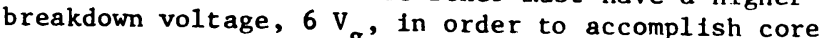
reset in the off-time $8.25 \mathrm{~T}$. If this same higher breakdown zener were employed in the forward converter operated at lower duty ratios, the voltage stresses would be higher than listed in Table 1 .

The conclusion is, therefore, that operation at output voltages other than $\mathrm{V}=\mathrm{V}$ in most respects increases the disparity between the new converter and the other two, and so the benefits to be obtained from the new converter configuration become even more striking, particularly when the additional superior features of the transformer design are taken into account.

\section{Multiple-output and coupled-inductor extenstion}

Once the isolation transformer has been introduced into the new converter as in Fig. 2, several extensions become obvious. There is no 
reason why the transformer should be limited to a single 1:1 winding, and multiple outputs of different voltages and polarities are easily obtained from multiple secondary windings, or from a tapped secondary winding as shown in Fig. 8. All of the benefits of the basic new :onverter are retained in the multiple-output versions; in particular, all the output currents and the input current are nonpulsating.

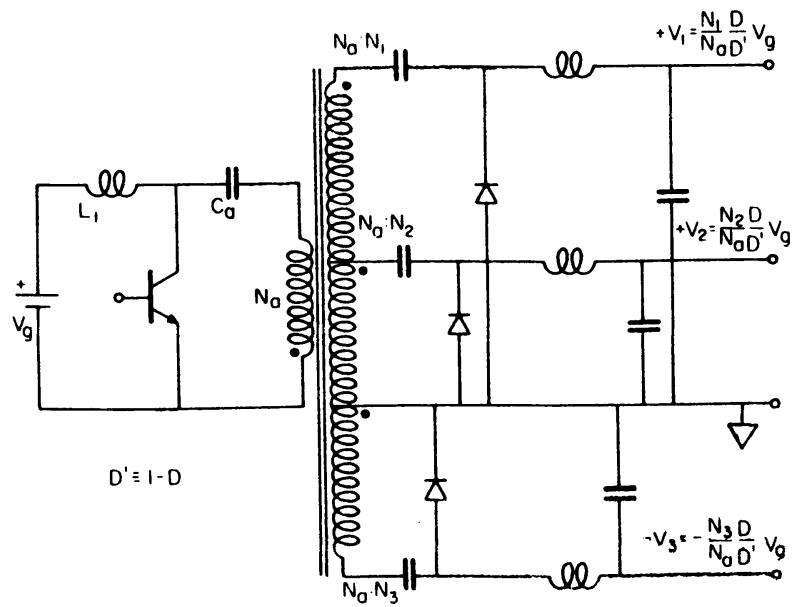

Fig. 8 Extension of the isolated new converter to multiple outputs with arbitrary ratios and polarities.

Another, less obvious, extension involves the possibility of inductor coupling. It has been shown in [3] that the input and output inductors in the basic converter of Fig. 1 can be wound on the same core, with consequent saving in size and weight. Moreover, by judicious selection of the turns ratio and coupling coefficient of the coupled inductors the switching ripple current can be "steered" to either the input or the output circuit, with the result that either the input or output ripple

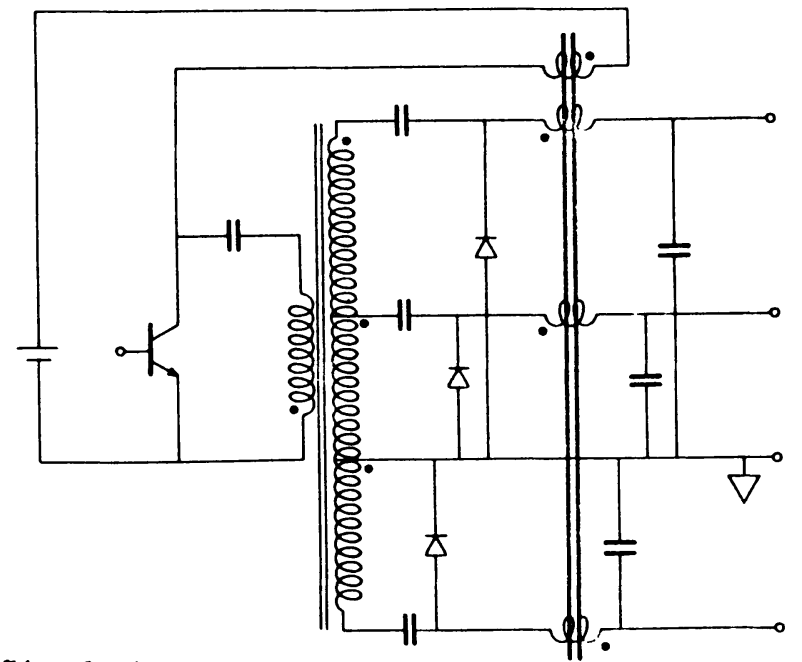

Fig. 9 Any or all of the input and output inductors in the multiple-output new converter can be coupled, which permits the switching current ripple to be "steered" towards or away from a given terminal. current can be reduced to zero, with obvious performance advantages.

The same opportunity exists in the transformerisolated multiple-output new converter: any or all of the Inductors can be coupled, that 1s, wound on the same core. Figure 9 shows the same circuit as in Fig. 8 with all of the inductors coupled in this manner, with consequent savings in size and weight. Again, by judiclous selection of the turns ratios and coupling coefficients, the ripple currents can be steered to, or away from, the input circuit or any of the outputs.

\section{Experimental results, and cross-regulation properties}

The test circult shown in Fig. 10 was constructed with a 1:1:1 18olation transformer, so that the output voltage $v_{1}$ is nominally equal to the output voltage $\nabla_{2}$. The power switch was operated at $50 \mathrm{kHz}$ with $D^{2} 0.5$, and the output voltages were $v_{1} \approx v_{2} \approx 15 \mathrm{v}$. Load currents up to $I_{1}=2 \wedge$ and $I_{2}^{1}=1^{2} A$ were drawn, for a maximum output power of $45 \mathrm{~W}$.

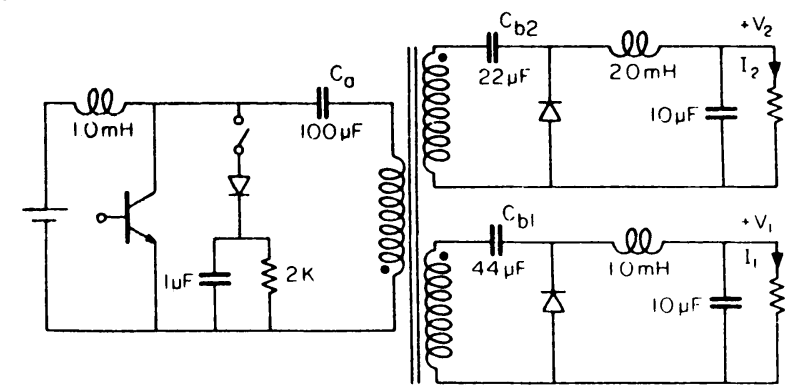

Fig. 10 Test circuit for a two-output isolated new converter, operated at up to $45 \mathrm{~W}$ output.

The transformer was designed to take maximum advantage of the low leakage potential. An (ungapped) Magnetics Inc. Square-Permalloy toroid, 51106-2D, was used; the windings were trifilar, each with 39 turns of \#26 AWG. The switching frequency of $50 \mathrm{kHz}$ is perhaps rather high for the 2-mil tape thickness, but interest was not centered on core losses in this test circuit. The winding factor is low so that all turns are as close to the core as possible; this results in a leakage inductance of about only $0.3 \mu \mathrm{H}$ per winding.

The "first-order" off-voltage sustained by the transistor switch is about $37 \mathrm{~V}$. When the circuit was operated at $I_{1}=I_{2}=1 \Lambda$ without the snubber, the additional leakage inductance spike was about $20 \mathrm{~V}$ and lasted about $0.12 \mu \mathrm{sec}$. With the snubber, the spike was reduced to about $3 \mathrm{~V}$.

One of the important aspects of multipleoutput converters is the cross-regulation property. Typically, such a converter is incorporated in a feedback loop in which one output is regulated and the others are "slaved." In this application, the regulated output remains essentially constant, but the slaved output voltages can vary substantially with the currents drawn from all the cutputs. 
Imperfect cross-regulation in conventional multiple-output converters results from, among other effects, inductor and transformer winding resistance, and unequal diode drops. In the new multiple-output converter, the separate coupling capacitances $\mathrm{C}_{\mathrm{b} 1}$ and $\mathrm{C}_{\mathrm{b} 2}$ in the test circuit of Fig. 10 contribute an additional term to the crossregulation property because of their unequal discharge during the switch on-interval $\mathrm{DT}_{8}$. It can easily be shown that the voltage difference $\Delta v_{2}-\Delta v_{1}$ arising from this effect is given by

$$
\Delta \mathrm{V}_{2}-\Delta \mathrm{V}_{1}=\left(\frac{\Delta \mathrm{I}_{1}}{\mathrm{C}_{\mathrm{b} 1}}-\frac{\Delta \mathrm{I}_{2}}{\mathrm{C}_{\mathrm{b} 2}}\right) \frac{\mathrm{D}^{2} \mathrm{~T}_{\mathrm{s}}}{2}
$$

Clearly, sufficiently large values of the capacitances $C_{b 1}$ and $C_{b 2}$ can be used to make the contribution to the cross-regulation from this ef fect arbitrarily small compared with the remaining effects.

Measurements were made of the cross-regulation and self-regulation properties of the test converter shown in Fig. 10. First, I was varied up to $2 \mathrm{~A}$, while the duty ratio was simultaneously adjusted to keep $\mathrm{V}_{1}$ constant at $15 \mathrm{~V}$ to simulate closed-1oop operation with $V_{1}$ as the regulated output. Also, $I_{2}$ was adjusted to remain at $1 \mathrm{~A}$. The resulting change in $V_{2}$ is shown in Fig. 11. The total change $\Delta \mathrm{V}_{2} 18$ about $0.9 \mathrm{~V}$ for $\mathrm{I}_{1}=0.2 \mathrm{~A}$ to $2 \mathrm{~A}$, or $\Delta \mathrm{I}_{1}^{2}=1.8 \mathrm{~A}$. From (1), only about $0.1 \mathrm{~V}$ of this change is accounted for by unequal discharge of $C_{b}$ and $\mathrm{C}_{2}$; the balance results from serles resistance and other parasitic effects.

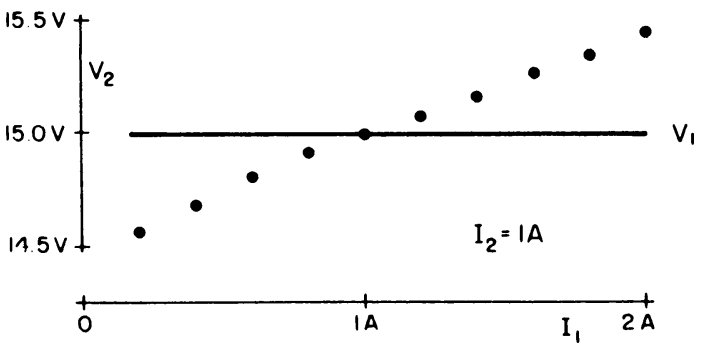

Fig. 11 Cross-regulation property of the circuit of Fig. 10: variation of $V_{2}$ as a function of $I_{1}$, with $V_{1}$ and $I_{2}$ maintained constant.

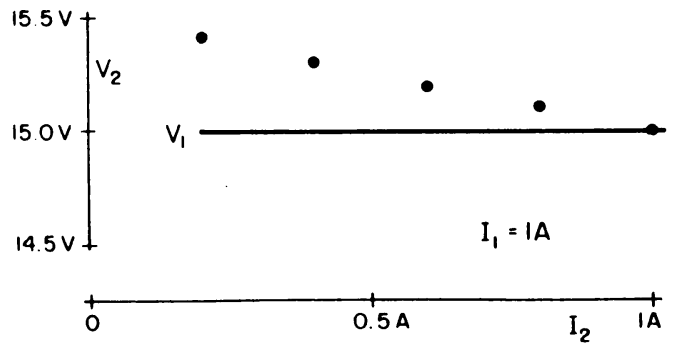

Fig. 12 Self-regulation property of the circuit of Fig. 10: variation of $V_{2}$ as a function of $I_{2}$, with $V_{1}$ and $I_{1}$ maintained constant.
Second, $I_{2}$ was varied up to $1 \mathrm{~A}$, while the duty ratio was simultaneously adjusted to keep $V_{1}$ constant at $15 \mathrm{~V}$, and $I_{1}$ was also adjusted to remain at $1 \mathrm{~A}$. The resulting change in $\mathrm{V}_{2}$ is shown in Fig. 12. The total change $\Delta V_{2}$ is less than $-0.5 \mathrm{~V}$ for $\Delta \mathrm{I}_{2}=0.8 \mathrm{~A}$, of which about a fifth is accounted for by unequal discharge of $\mathrm{C}_{\mathrm{b} 1}$ and $\mathrm{C}_{\mathrm{b} 2}$.

It is therefore seen that in both the crossregulation and self-regulation properties the contribution from unequal coupling capacitor charging and discharging is quite small, and is achieved with secondary coupling capacitors of only $44 \mu \mathrm{F}$ and $22 \mu \mathrm{F}$. Larger capacitors, which could easily have been used, would have reduced this effect to negligibility.

\section{Conclusion}

A recently introduced optimum-topology dc-to-dc switching converter has been extended in a simple and elegant manner to incorporate dc isolation and multiple outputs, with retention of a single switch.

Compared to the conventional single-transistor transformer-1solated forward and flyback converters the new converter has substantial advantages of equal or lower transistor and diode current and voltage stress levels, and also of equal or lower capacitor ripple current stress level. Furthermore, smaller core and winding sizes for the 1solation transformer can be employed in the new converter, which also has lower core and copper losses than in the forward and flyback converters. A detailed discussion of these comparisons is given.

The possibility of coupling the input and output Inductors, which has previously been shown to lead to reduced, even zero, input or output ripple current in the new converter, is also available in the isolated multiple-output extensions, in which any or all of the input and output inductors can be wound on the same core.

Experimental results are given for a twooutput isolated new converter, together with measurements of the cross-regulation properties which are of Importance when a multiple-output converter is employed in a feedback loop in which only one output is regulated, as is commonly used in computer power supplies. Work is continuing in all these areas.

Several students in the California Institute of Technology Power Electronics Research Group have participated in various phases of this work. Special acknowledgment 18 made of the work of graduate student Shi-Ping Hsu, who contributed the test circuits and made the experimental measurements. 


\section{REFERENCES}

[1] Slobodan Cuk and R. D. Middlebrook, "A New Optimum Topology Switching Dc-to-Dc Converter," IEEE Power Electronics Special ists Conference, 1977 Record, pp. 160-179 (IEEE Publication No. $77 \mathrm{CH}$ 1213-8 AES).

[2] Slobodan Ćuk and R. D. Middlebrook, "Dc-to-Dc Switching Converter," U.S. Patent applied for, California Institute of Technology, filed Sept. 27, 1977.

[3] Slobodan Ćuk and R. D. Middlebrook, "CoupledInductor and Other Extensions of a New OptImum Topology Switching Dc-to-Dc Converter," IEEE Industry Applications Society Annual Meeting, 1977 Record, pp. 1110-1122 (IEEE Publication No. $77 \mathrm{CH}$ 1246-8-IA).
[4] Slobodan Ćuk and Robert Erickson, "A Conceptually New High-Frequency Switched-Mode Power Amplifier Technique Eliminates Current Ripple," Proceedings of the Fifth National Solid-State Power Conversion Conference (POWERCON 5), May 1978; pp. G3.1-G3.22.

[5] R. D. Middlebrook, Slobodan Cuk, and W. Behen, "A New Battery Charger/Discharger Converter," IEEE Power Electronics Specialists Conference, 1978 Record (accompanylng paper). 